\title{
Pilocytic Astrocytoma Presenting as an Orbital Encephalocele: A Case Report
}

\author{
Amy Bruzek $^{\mathrm{a}} \quad$ Daniel Shepherd $^{\mathrm{b}} \quad$ Jamie Van Gompel ${ }^{\mathrm{c}} \quad$ Mark Jentoft $^{\mathrm{d}}$ \\ ${ }^{a}$ Virginia Commonwealth University, Richmond, Va., ${ }^{b}$ Mayo Clinic and Departments of \\ ${ }^{\mathrm{c}}$ Neurosurgery and ${ }^{\mathrm{d}}$ Anatomic Pathology, Mayo Clinic, Rochester, Minn., USA
}

\section{Key Words}

Orbital encephalocele $\cdot$ Pilocytic astrocytoma $\cdot$ Traumatic encephalocele $\cdot$ Anterior encephalocele

\begin{abstract}
We describe the case of a 29-year-old male who presented with new-onset seizures. He was subsequently found to have an orbital encephalocele containing a focus of pilocytic astrocytoma. We believe that this is the first report of a pilocytic astrocytoma located within the orbit that did not originate from the optic pathway. It is also the first case of a pilocytic astrocytoma completely contained within an encephalocele. This case suggests a close pathological examination of encephaloceles for underlying diseases.

(c) 2015 S. Karger AG, Basel
\end{abstract}

\section{Introduction}

An orbital encephalocele is a rare variant of encephalocele in which there is a herniated mass of brain and meninges into the orbit $[1,2]$. The encephalocele may arise through natural foramina such as the superior orbital fissure or the optic foramen (i.e. posterior orbital encephalocele) or bony defects in the orbital roof (i.e. anterior orbital encephalocele) [2-4]. Most orbital encephaloceles are thought to be of congenital origin; posttraumatic cases have also been reported $[5,6]$.

We present a case of an orbital encephalocele which was later pathologically identified with a small focus on pilocytic astrocytoma. Pilocytic astrocytomas comprise $2.3 \%$ of adult brain tumors [7]. They have been reported to occur in the optic nerve or optic chiasm, but do 
Bruzek et al.: Pilocytic Astrocytoma Presenting as an Orbital Encephalocele: A Case Report

not commonly occur in the orbit [8]. To our knowledge, there has never been a case report of a pilocytic astrocytoma being discovered within an orbital encephalocele.

\section{Case Report}

We describe the case of a 29-year-old male who presented with new-onset, multiple tonic-clonic seizures. His past medical history was significant - multiple sports-related concussions as a result of playing competitive ice hockey and a remote high-velocity motor vehicle accident in which he was a restrained passenger. He reported no loss of consciousness at the time of the incident. On examination, the patient had slight right-sided ptosis and subjective movement-related diplopia that resolved with gaze fixation. He was otherwise neurologically intact and without any other abnormal physical examination findings. A head CT was performed upon arrival to the emergency department which revealed a right-sided hyperdense encephalocele with a protrusion into the orbit (fig. 1). An MRI confirmed the rightsided encephalocele; it revealed a herniation of the frontal lobe into the orbit with a displacement of the globe and a superior rectus muscle inferiorly as well as blurring of the gray matter in the encephalocele (fig. 2). On T2 images, there was a signal change around the area of strangulation (fig. 2), but DWI did not reveal a diffusion restriction.

The patient was taken to the operating room for surgical resection and the pathological interpretation of the mass. A standard right frontal craniotomy was performed. The encephalocele was readily identified upon exploration of the orbital roof. Grossly, the encephalocele appeared cystic with intermixed vasculature and was densely attached to the periorbita. After the encephalocele was mobilized from the orbit, intraoperative electrocorticography was conducted. Interlesional and some diffuse frontal spiking were observed. The extruded encephalocele was resected in an en-bloc fashion. The dura was reconstructed using a pericranium. The bony defect was repaired using a right $\mathrm{OZ}$ Medpor implant and vascularized pericranium. The specimen was then sent to pathology for further analysis.

The patient tolerated the procedure well and was extubated without complications. There were no postoperative seizures following surgery. Pathological findings confirmed disorganized neuroglial tissue consistent with an encephalocele (fig. 3). However, there was a $0.5 \mathrm{~cm}$ focus of low-grade pilocytic astrocytoma encased by the encephalocele, which did not involve surrounding normal structures such as the optic pathway. Follow-up care included an MRI at 3 months and yearly thereafter.

\section{Discussion}

Anterior encephaloceles, especially the ones that project into the orbit as in our patient's case without frontal sinus fractures, are rare [2, 4]. One study of 123 pediatric and 10 adult patients with anterior encephaloceles found orbital encephaloceles in only 6 cases [9]. Orbital encephaloceles may be congenital or acquired, with congenital encephaloceles more likely to present in early childhood. In the adult population, most encephaloceles are sporadic, and only a minority result from trauma. Traumatic orbital encephaloceles are a quite rare; there are only 15 cases reported in the literature thus far, including both pediatric and adult cases [5]. An orbital encephalocele due to trauma may develop acutely or may develop many years later as the arachnoid and tissue gradually herniate, or as the fracture in the orbital wall grows over time $[5,6]$. Although our patient had suffered injuries from a motor vehicle 
Bruzek et al.: Pilocytic Astrocytoma Presenting as an Orbital Encephalocele: A Case Report

accident 10 years earlier, we could not determine whether his orbital encephalocele was traumatic or acquired in etiology.

Pilocytic astrocytoma is a benign neoplasm that most often occurs in the cerebellum and in children [8]. Pilocytic astrocytomas are rare in adults and account for approximately $2 \%$ of adult brain tumors $[8,10]$. Most often, pilocytic astrocytomas in adults occur in the cerebellum, followed by the optic pathway (namely the chiasm), brainstem, or spinal cord [8]. Typically, orbital pilocytic astrocytomas arise from some component of the optic pathway. Our patient's orbital pilocytic astrocytoma was not involved with the optic pathway.

Here we presented a patient who was evaluated for seizures, ptosis, and diplopia, who was found to have not only an orbital encephalocele but also a pilocytic astrocytoma within the encephalocele. Although we do not know which developed first in our patient, primary treatment for both encephaloceles and low-grade pilocytic astrocytomas is surgical resection of the abnormal tissue. Following the complete resection of the encephalocele and the surrounding epileptogenic frontal lobe tissue, the patient had an excellent recovery with the resolution of his diplopia and his seizures. Piloid gliosis may occur as a result of chronic processes like an encephalocele; however, our case exhibited an increased cellularity and clearly involved the leptomeninges, which are features favoring a pilocytic astrocytoma. It is unclear whether the tumor caused the bony erosion to result in an encephalocele, or if the chronic inflammation of the encephalocele produced an environment which facilitated the formation of the pilocytic astrocytoma. Although the two entities may have occurred in the same location without causation, it is difficult to believe that one entity did not lead to the development of the other. We believe that this is the first case report of a pilocytic astrocytoma within an orbital encephalocele. Although we do not know the general significance of our patient's findings, we recommend a close pathological examination of orbital encephaloceles.

\section{Disclosure Statement}

The authors declare no conflicts of interest.

\section{References}

1 Singh AK, Upadhyaya DN: Sincipital encephaloceles. J Craniofac Surg 2009;20:1851-1855.

2 Katano H, Aihara N, Takeuchi Y, et al: Tailor-made orbitocranioplasty for a sphenorbital encephalocele presenting as pulsatile exophthalmos. Case report. J Neurosurg 2007;106:126-130.

-3 Consul BN, Kulshrestha OP: Orbital meningocele. Br J Ophthalmol 1965;49:374-376.

4 Sharma M, Mally R, Velho V, Agarwal V: Spheno-orbital encephalocele: a rare entity - a case report and review of literature. Asian J Neurosurg 2014;9:108-111.

-5 Antonelli V, Cremonini AM, Campobassi A, Pascarella R, Zofrea G, Servadei F: Traumatic encephalocele related to orbital roof fractures: report of six cases and literature review. Surg Neurol 2002;57:117-125

-6 Jaiswal M, Sundar IV, Gandhi A, Purohit D, Mittal RS: Acute traumatic orbital encephalocele: a case report with review of literature. J Neurosci Rural Pract 2013;4:467-470.

-7 Stuer C, Vilz B, Majores M, et al: Frequent recurrence and progression in pilocytic astrocytoma in adults. Cancer 2007;110:2799-2808.

-8 Ye JM, Ye MJ, Kranz S, Lo P: A 10 year retrospective study of surgical outcomes of adult intracranial pilocytic astrocytoma. J Clin Neurosci 2014;21:2160-2164.

-9 Mahapatra AK: Anterior encephalocele - AIIMS experience a series of 133 patients. J Pediatr Neurosci 2011;6(suppl 1):S27-S30.

-10 Nagaishi M, Sugiura Y, I Takano, Tanaka Y, Suzuki K, Yokoo H, Hyodo A: Clinicopathological and molecular features of malignant optic pathway glioma in an adult. J Clin Neurosci 2015;22:207-209. 
Bruzek et al.: Pilocytic Astrocytoma Presenting as an Orbital Encephalocele: A Case Report
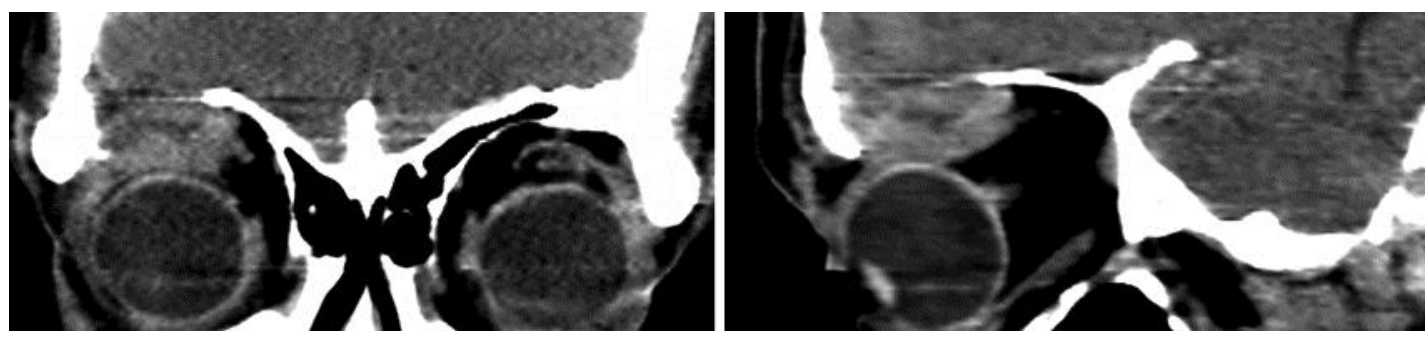

Fig. 1. CT scan demonstrating the right-sided orbital mass, with the frontal lobe herniating into the superior orbit.
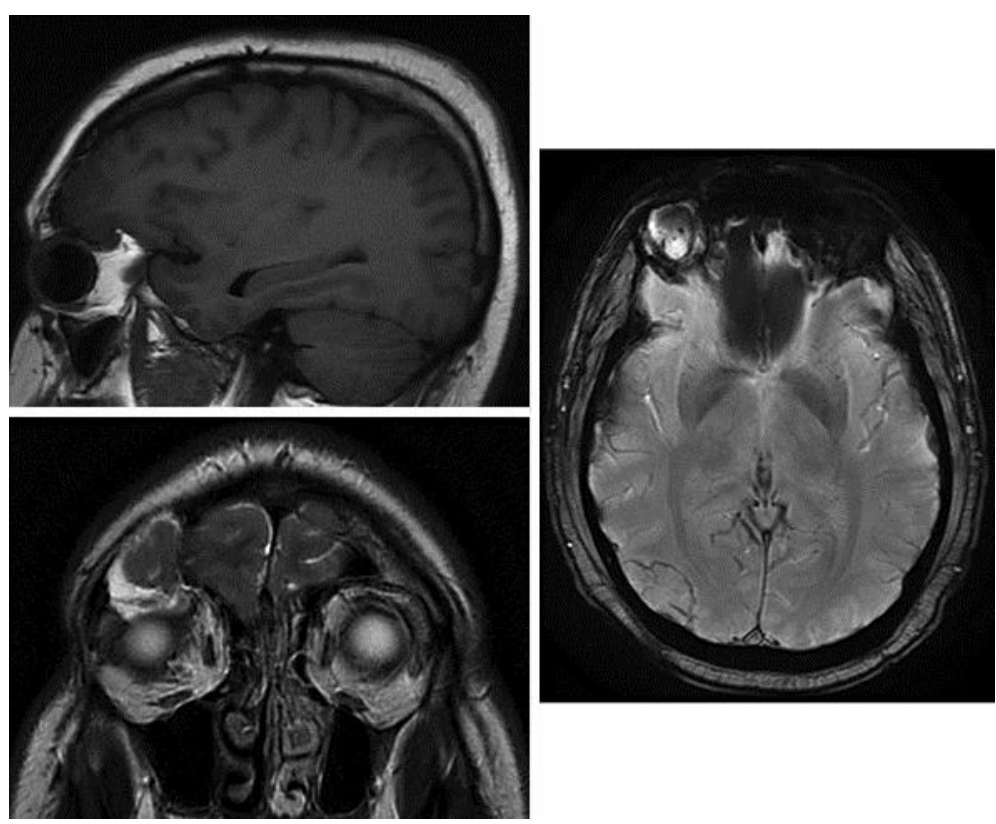

Fig. 2. MRI, T1, and T2 images showing the right lateral orbital encephalocele. 


\section{Case Reports in Neurology}

\begin{tabular}{l|l}
\hline \multicolumn{2}{l|}{ Case Rep Neurol 2015;7:90-94 } \\
\hline DOI: $10.1159 / 000381943$ & $\begin{array}{l}\text { C } 2015 \text { S. Karger AG, Basel } \\
\text { www.karger.com/crn }\end{array}$ \\
\hline
\end{tabular}

Bruzek et al.: Pilocytic Astrocytoma Presenting as an Orbital Encephalocele: A Case Report
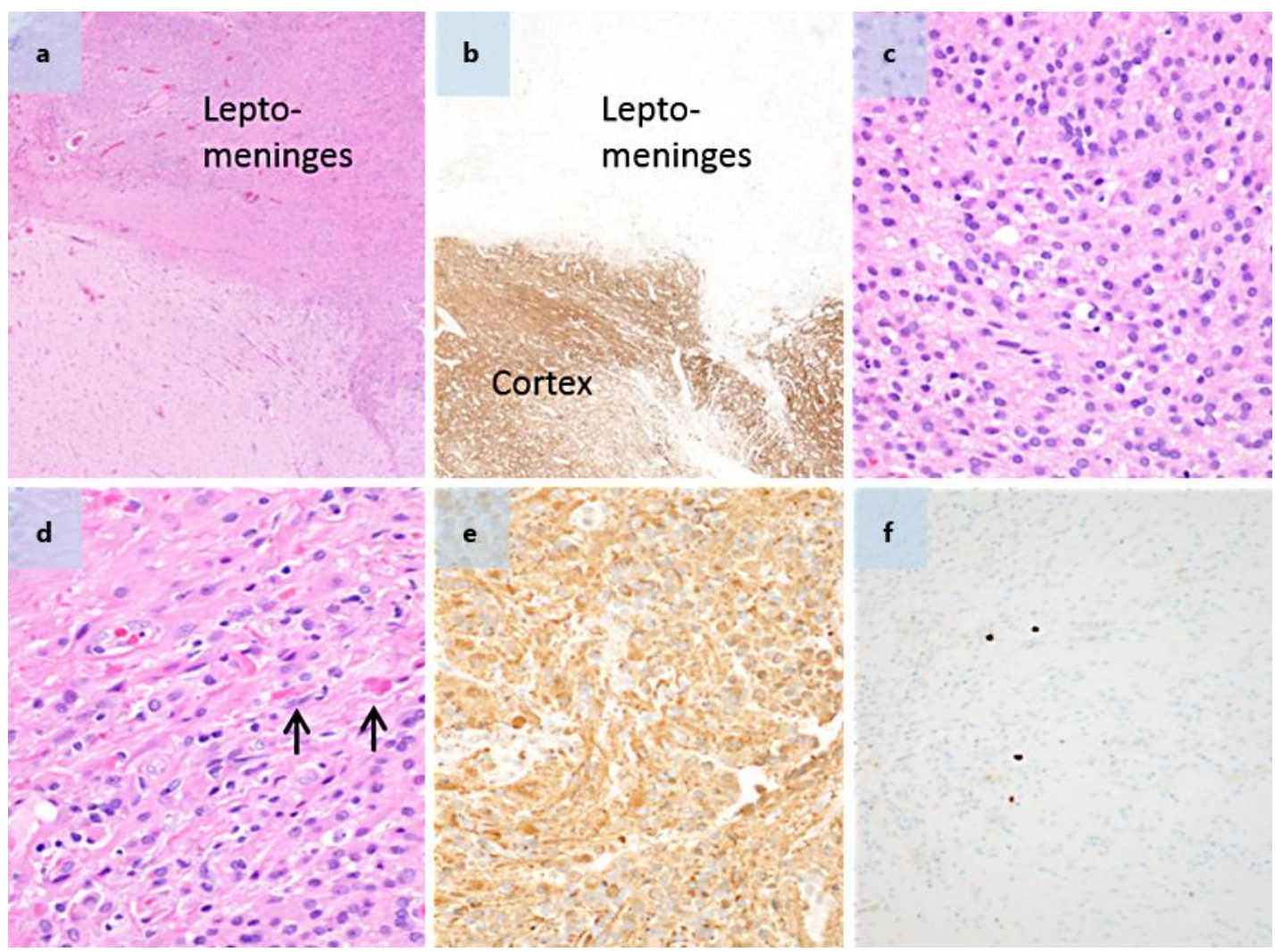

$f$

Fig. 3. a, b HE and neurofilament stains, respectively $\times 4$ objective. The neurofilament stain with paired HE highlights that the tumor predominantly involves the leptomeninges. c HE. $\times 40$ objective. Much of the tumor was composed of monotonous-appearing cells with round and relatively regular nuclei. $\mathbf{d}$ HE. $\times 40$ objective. In areas of the tumor, the cells had slightly more elongated cell nuclei, and the tumor contained Rosenthal fibers (arrows). e GFAP. $\times 40$ objective. The tumor cells are strongly positive for GFAP. $\mathbf{f}$ Ki- 67 . $\times 20$ objective. The tumor had a low level of proliferative activity which is highlighted by only occasional scattered Ki-67-positive cells. 